\title{
SocArXiv
}

Preprint : May 24, 2021

URL/DOI GOES HERE

\section{Dis-origined Materials: The Role and Invisibilization of Extraction in Technoscience}

\author{
Emma McKay* \\ McGill University
}

\begin{abstract}
In new materialist STS, researchers recognize and investigate the liveliness, agency, and ongoing historicity of matter in the lab. Through the work of extraction studies, we know that much of this matter is violently pulled from the ground - the metals in electronic devices, for instance, were cut out of the earth. Previous work in new materialist STS has critiqued the construction of the 'object' as obscuring how things work and are made, yet the role of extraction in things has gone largely unacknowledged. In this paper, I argue that extraction is a core element of contemporary technoscience. I define the term dis-origining to analytically describe the way that objects are made to seem as if they come from nowhere, within and far beyond the STS literature, comparing this term with related concepts including Haraway's (1988) god-trick and Marx's commodity fetish. Seeing extraction in the world around us and naming the ways that socio-ecologies have been invisibilized may help us address the immense violences wrought in making contemporary technosciences.
\end{abstract}

Keywords: extraction, science and technology studies, new materialism, place.

\section{Introduction}

You are reading or listening to this on a computer of some kind. Let us say you are reading on a screen. The closest part of the screen to you is a type of plastic. Behind that there is a very thin layer of indium tin oxide. Inside the hard plastic case there are dozens more metals. Copper in the wiring, and gold too. Palladium, platinum, silver, zinc, arsenic. Lithium and cobalt in batteries. Neodymium, yttrium, and praseodymium in magnets and motors. Each of these materials has its own lively ability to shape the world around it, with its own constraints - its own agency, as new materialists say. But each of these materials is also cut out of the ground

\footnotetext{
*Contact: emma.m.mckay@gmail.com
} 
for an immense carbon cost, with impressively violent consequences for local socio-ecologies.

The removal of materials from socio-ecologies at large scales is called extraction. This taking from place is a crisis. Politically, extraction is used to provide wealthy colonizer classes with stuff at the direct expense of poor colonized classes and land. Ecologically, all extractive industries are responsible for about $30 \%$ of $\mathrm{CO}_{2}$ equivalent emissions globally, with metal mining producing $10 \%$ all by itself (Oberle et al. 2019). Sites produce immense amounts of solid and toxic waste which is often insecurely stored (MiningWatch Canada 2020). And communities, especially Indigenous ones, often resist mine sites, sometimes experiencing violent backlash in the process (Global Witness 2020).

Yet there is a structural disconnect between the violent extraction of matter from emplaced networks of life and the way that things made of that matter are thought about. For many things, and for many people, it is as if things come from nowhere. Worse than that pervasive discourse, it is nearly impossible to know where things come from if you care to find out. I began to see this invisibility many years ago as I started to talk about the social and environmental impacts of doing physics with my then-peers. There were metals in all of these labs, and the computers researchers were using, but the origins of the metals were not there.

I turned to science and technology studies (STS) to investigate the way the world was seen in these labs and to extraction studies to learn more about where these materials came from. But these fields were infrequently brought together. I saw again a too-frequent treatment of lively materials as if they came from nowhere. Only a few materials, like cobalt from the Democratic Republic of the Congo, or, more recently, lithium from Bolivia, had their origins discussed.

How can we talk about this sense that things come from nowhere? It is almost a lack of a sense of something, an invisibilization. Many terms already exist to describe structural obfuscation. For example, the Marxist commodity fetish describes the erasure of social histories of production through capitalist exchange. But this and the other language I found did not adequately engage with a sense of place - after all, lithium's history is not just social. Lithium is from specific socio-ecologies, including the role it plays in aquifers in the Atacama, the driest desert in the world. Neither did these terms engage sufficiently with extraction. Lithium, again, is not just produced. It is extracted from place.

In this paper, I offer new language to describe widespread structures and discourse about materials that make it seem as if they come from nowhere and that invisibilize extraction. This language is the word dis-origining. Dis-origined materials not only appear in popular discourse unconnected to their place of origin, but also have information about their origin so stripped away that it can be nearly impossible to find. More than this, they have been physically removed from their origin in generally harmful and often irreversible ways.

Throughout the paper, I focus on the role of metals in technoscience, as opposed to other materials and other uses of them. I focus on technoscience because of my personal interest in justifications of physics and STS theory. Many new materialists, focused on process and ongoing historicity, focus more on the lively productions of the materials they observe, to the exclusion of the extraction which produced them as they are. New materialist scholars like Anusas and Ingold (2013) and Barad (2007) refuse the idea of the object, recognizing that this concept hides processes that make things and make them up. This can be readily extended to include the origin that materials were extracted from with the language introduced in this paper. I focus on metals because they supply so much of the liveliness of technoscience, especially physics labs, but their emplaced histories and futures so rarely appear in discussions 
of technology. Still, all extraction is important to attend to.

In addition to providing useful language, the goal of this paper is to argue that responsibility in (studying) technoscience requires paying attention to and orienting ourselves against extraction.

I begin with defining extraction and discussing its links to capitalism, colonialism, and production in section 2. I argue that extraction is inherent in contemporary material technoscience. Then, in section 3, I turn to what extraction takes from: the origin of things. I discuss the influence of Haudenosaunee and Anishnaabe land on my thought about place and relationships, and my decision to use the concept of origin in recognition of my limited understanding of these confederacies' law and thought.

In section 4, I define dis-origining in detail. It has a discourse, where things appear to be from nowhere. It is structural stripping of information, both through the intentional actions of corporations and the physical nature of extraction. It is also compartmentalized reasoning, where knowing about the origin of a material does not necessarily figure into decisions about what to do with something that uses that material.

I then compare dis-origining with several relevant theoretical concepts in section 5: Haraway's (1988) god-trick, eco-marxist's environmental alienation, Marx's (1976) commodity fetish, and resource geographers' dissociation (Ibert et al. 2019).

Finally, in section 6 I discuss the responsibility that exists towards sites of extraction for technoscience. The lab only exists because of extraction. What would being responsible in this relationship look like? Trying to tell the story of materials, something I am here calling re-origining, could be helpful up to a point. I finish with conclusions in section 7 .

\section{Extraction in technoscience}

Extraction is "the over-exploitation of nature (including both human labour and non-human resources) to such an extent that it undermines its conditions of existence over time" (KilloranMcKibbin and Zalik 2016, p. 2). In other words, it is the harmful removal of material, time, or good relations from a place, generally for the benefit of another place. Here are a few straightforward examples. Intensive agriculture typically uses more nutrients than are easily replaced in the soil; then, the food produced is shipped elsewhere, and its nutrients are not returned to the soil, which degrades (Bellamy-Foster and Clark 2004). Mining cuts rock out of the earth, separates out undesired parts, which typically fester in toxic pools, and ships the desired parts around the world for further refining and production into objects. A wage labourer spends many hours in the week producing stuff for a capitalist to sell; their time is extracted from them.

Extraction is not limited in its existence or effect to these straightforward examples, or to the industries typically considered 'extractive' like mining. Agricultural extraction does not only exist at the site of intensive monoculture - it is spread throughout the food systems which involve and depend on this extraction. Clearcutting is not only an issue of the logging industry, but also of housing and everything else we build with wood. Everything that is made of metals is completely indivisible from mining. This is a main point of extraction scholars KilloranMcKibbin and Zalik (2016): in sites of production, labour, and creation, extraction is usually present.

Extraction is a core element of capitalism. Capitalists extract time from workers. Capital also 
depends on materials to do any kind of production. These materials are considered external to capital's calculations - they are merely sources of value to be exploited, not elements of rich networks of relations.

It is also a core element of colonialism. Colonizing classes seek the benefit of land, extracted from its relationships with Indigenous populations, and often cast in terms of 'resources' to be violently and excessively exploited (Seawright 2014).

The current political economic instantiation of extraction on a global scale which typically moves materials out of the hands of the worker and colonized classes into the hands of the capitalist and colonizing classes is called extractivism (Gudynas 2013; Arboleda 2020). Extractivism also refers to the ideology on which these structures rest. Extractivism as it currently exists and is understood is indivisible from capitalism and colonialism.

This setup is enacted together by state, inter-state, and corporate actors. Corporations and states both have built sturdy legal and labour structures to ensure the balance of power is in favour of the extractors at the expense of the extracted-from (e.g. Girvan 1976). The Canadian state is notable in this regard. The land now illegally occupied by this state was originally colonized by the British and French as they sought resources to support enormous empires. They have continued to exploit surviving Indigenous nations well after their efforts at genocide began (e.g. Bernauer 2019; Cameron and Levitan 2014; INET 2017; Kuyek 2019). These efforts are by no means limited by the colonial border, either. International and national law have been used to support violent efforts by corporations to operate mines in South America, often against the will of local communities (e.g. Gordon and Webber 2018; Moore and Perez-Rocha 2019; Cervantes and Zalik 2018). Resource-intensive practices in Canada like wealthy settler lifestyles and militarist research are enabled by these extractive practices.

The depth of extractive logics and practice in various political and social arenas is extensive. These logics create sharp divisions. The sphere of human activity, for instance, is posited as separate, somehow, from the rest of the earth. The institution of these separations are crucial to the process of extraction. Divisions are "powerful ways of organizing nature... nature becomes subsumed to capital, with rivers polluted, glaciers destroyed, crops diminished, workers laid off and impoverished, and communities in continuous anxiety and stress" (Arboleda 2020, p. 194). I will return to these logics below as I discuss dis-origining.

Violence is an inherent part of extraction. It is malleable for some kinds of extractionlumber, for instance, does not need to come from clear cuts. In the specific case of mining, socio-ecological damage is unavoidable. Currently, the machinery used to mine for metals (i.e. not including mining for oil and gas or aggregates like gravel) contributes a full $10 \%$ of annual energy-related greenhouse emissions; clearning, digging, and disposal for mines causes a huge amount of habitat loss and extinction (Oberle et al. 2019; Azadi et al. 2020). About 40 million people worldwide are artisanal, or small-scale, miners (Fritz et al. 2018). An enormous number of them work in toxic and dangerous situations, many without the support of basic PPE, supervisors, health \& safety regulations, or healthcare. An even larger number of people are affected by the pollution left behind at sites where materials are extracted and processed. Though the scale of this damage is certainly reducable through technologies of carbon capture and 'renewable' energy, mining will never not involve using a huge amount of energy to clear land of life and excise rock from the ground.

Another way that violence inheres in extraction is in its drive to overcome the resistance that local socio-ecosystems often exert against extractive projects. Militaries are often wielded to 
force extraction, or to force the profits into certain corporate hands (Mitchell 2009). Examples include the many wars America has started for oil, or the RCMP wielding weapons to force a pipeline through Wet'suwet'en land (Nolan 2020; Hosgood 2020). This leads in turn to a third way that violence and extraction are intertwined: metals are used to construct weapons fueled by oil (Slowinski et al. 2013; Carpenter 2012).

Though some parts of extraction are inherent, others are contingent. The current economic instantiation is capitalist, but other extractive economic systems are possible. It is thus crucial to be politically and scholastically oriented not only against capital, but also against extraction. Being against extraction means, in other language, being invested in generative systems, which sustain and create diverse lives rather than extract from and damage them (e.g. Eglash et al. 2017; Simpson 2011). This is a central element of Indigenous resurgence, which is focused not only on removing politically dominating colonial forces from Indigenous life, but also (re)building non-extractive ways of being with the world (e.g. Coulthard 2014; Simpson 2008). Including extraction in our understanding of technoscience thus brings something crucial. In almost every piece of lively material technology there are pieces from the ground, where ecological cycles were broken, toxic elements likely leeched, workers exploited and likely harmed, and habitat destroyed. Parts of this are inherent, unavoidable. A (post-)extractivist lens provides a political ecological orientation for STS against this kind of violence as it is present in the technologies and sciences we study.

\section{What is an origin?: Ecology, land, and rocks}

Place is clearly important in extraction. It is a violence of removal from somewhere, after all. Much of the violence to be opposed happens in the places materials are removed from - their origins.

What is an origin of something? It is not a beginning, because beginnings are not real. There is always more history, more of a story to tell. Some partial beginnings can be justified, though. Take the coalescing of small rocks into planetoids into the earth and the moon. The beginning is not sharp, but it is there.

There is little else that is as sharp as the birth of the planet. Of course, this points to one origin: earth, our only planet. It is only an origin because of the relationships that have since made it up, which give it meaning. To identify any partial origin of anything else, then, we can look to relationships that make up a place. We could think of a network of relationships that sustain life, tied to geological and geographical specificities and long-standing bio-cultural inhabitants. These are socio-ecologies, systems of exchange and being among plant, human, bug, bird, rock, water. It is easy for some things to have more than one origin, like it is easy for birds to fly far away, or for humans to migrate, or for climates to change on the surface of a mountain.

It is harder for some things to move. The friction in moving or staying is important in getting a sense for origin. Rocks move sometimes, in volcanic cataclysms and earthquakes, or they move very slowly, maybe a few centimetres a year as a part of a great continental plate. The role that rocks play in most ecologies they are a part of is as a base, a bottom, not an impermeable surface, but an eroding, hole-filled, messy foundation for soil, root, and water (Fox et al. 2020).

So what is there to know about where something, especially a metal, comes from? There are all of its various origins, its networks of social ecological relationships. There are the 
socio-ecologies it left, or was cut out of, and the effect of the cutting on the relationships. What new relationships were created? A mine owner may have cultivated a new business relationship, river-dwelling creatures may become closer with mercury, mine workers may find that breathing is a different experience. And then it continues, beyond the mine site. An ore cut out of the ground has new relationships with shipping containers, ports, cranes, hot fires, chemical amalgams, retailers, manufacturers, scientists, tech designers, assembly line workers, tech users, garbage boxes, more shipping containers, and e-waste handlers, and all of the ecologies that all of these bodies are a part of.

The origin of my thinking about origins is relevant: where material stuff comes from is important to be able to respond to the relations that produced that stuff, and the same is true for theory. I am a settler who grew up in an extremely disconnected lifestyle, where I knew very little history, local ecology, or intimate relationships. Over the past twelve or so years, the Indigenous work that I have read and heard and the conversations that I have had made a great impact on me. While I studied at the University of Waterloo, I frequently went to events at Shatitsirótha', the Indigenous Student Centre. I had some conversations, but I was mostly quiet, listening. I learned a bit about land, nations, history, and law. That little bit was enough to drastically shift the way that I thought about the world, in concert with the other ways that I was changing my social and political knowledge and position through campus activism and STS. I came to see connections where I had previously been taught there were none-between plants and human, politics and physics, history and future and now. I came to feel that somehow playing a part in decolonization was an imperative, and I brought that feeling and my limited knowledge to various activist and academic spaces.

People and works who have been really influential include Rene Meshake (Anishnaabe), who taught that you should "let the story change you" (Meshake 2016). Hill (2017) (Haudenosaunee) writes extensively about Haudenosaunee history and connection to land including the connection between each being involved in the entire system of life. Vanessa Watts (2013) (Anishnaabe) describes the inseparability of Anishnaabe people and thought from the literal places in which it has been and continues to be formed. Those places include the nations of people, animal, plant, water, and rock, which are all autonomous. Camastro (2019) (Anishnaabe) taught me a great deal about the Dish With One Spoon, law which covers land around the Great Lakes. That law includes a sense of land as place made up of connected nations with a very long past and a very long future.

This work made clear that there were really important things about materials: long pasts and futures, roles in socio-ecologies, responsibilities associated with those roles, and the specificity of all of this to place. Many of these things were also present in other work and life. Of course, there are many Indigenous epistemologies deeply interwoven with local land and ecologies from all around the world (e.g. Ingersoll 2016; Kuokkanen 2000; Denzin et al. 2008). Eco-marxists write about metabolic rifts, which emphasize the unique role that many aspects of socioecologies have (e.g. Bellamy-Foster and Clark 2004). Feminist science studies scholars write about responsibility in specific relationships (Haraway 2016). Educators write about teaching with place (Paperson 2014; Gruenewald 2003). In trying to make sense of the world in front of me, I took all of these things together, even though there are quite a lot of contradictions between the works, especially in their cultural engagements.

If I want to talk about origin, I had better talk about pasts and futures, roles, and so on. But I am not able to use something like Indigenous land frameworks to talk about it. I do not 
have the relationships and education to be able to do so. I have mostly settler ties and am still dealing with my very settler upbringing. I do not have the legal or spiritual background to engage deeply in a concept which is legal and spiritual. Still, I cannot act like this work was not important. Hence, this idea of origin with wide acknowledgement of my path to it, without claiming to be using or contributing to Indigenous land frameworks. ${ }^{1}$

So, origins are physical places with specific interwoven socio-ecological relationships. They have long pasts and futures, even though they change. Origins differ for different bodies, like rocks are much harder to move than humans. They are important to attend to in technoscience because they are where the violence of extraction is most pertinent.

\section{Defining dis-origining}

To extract something is to remove it from its socio-ecology, to violently end its ability to respond in its many relationships. To dis-origin something is to make it seem as if it came from nowhere, as if it never had mutually supportive relationships of a stable ecology or mutually destructive relationships of heavy metals smelting. Dis-origining has three major parts. There is a discourse, or almost the absence of a discourse, about where things come from. Then there is the lack of information about where something came from. These parts are sometimes intentional, sometimes merely difficult to avoid, and sometimes inherent to the process of extraction. Finally, there is compartmentalization. Even when people know something about the violence of where something comes from, they often do not use that knowledge in acting around that thing. In the following subsections, I theorize these three parts of dis-origining.

\subsection{The discourse}

The first part of dis-origining is the discourse. It is not just that people do not know where things come from; it is that they often do not even think to ask. It can be identified by many people with a simple exercise of looking around a room familiar to you. How many objects do you know the origin of beyond a retailer or a person who gave them to you? It can be tricky to see all of the stuff and what makes it up. Consider each piece of the computer you likely used to access this paper, the walls of the room and the wires, pipes, and insulation inside of them, and not just food but all the paper, plastic, and glass it is housed in. For how many objects had you considered their origin before?

This discourse is made clear partly through which materials we are able to talk about the origin of. Food's origins are discussed more than those of its packaging. Some of this is due to positive associations, like farmers at markets advertising locally-grown produce. Some of this is the result of concerted efforts of activists highlighting ecological devastation through practices like the burning of rainforests for palm oil production. Some metals' origins are also discussed. So-called 'conflict minerals' are fairly well-known to be mined in the Democratic Republic of the Congo. Several of these mines are operated by militias; the profits from the sale of the minerals go towards funding local conflicts. This has received international attention (European Commission 2020). America wrote conflict mineral legislation into the 2010 Dodd-Frank Act, requiring that ore be tagged on-site in the DRC to indicate it came

\footnotetext{
${ }^{1}$ Is this use of theory extractive? I am not sure. It could be. Is it generative? It seems to have the potential to be. Whatever it is, it is something I am trying to take responsibility for.
} 
from an approved mine. This had essentially no impact on reducing the local conflict, but did serve to tie the conflict to that place (Radley and Vogel 2015).

Many of the people who have worked to highlight the origins of these materials were likely wellintentioned, but these examples of problematic origin can exceptionalize harmful extraction. That is, conflict minerals are positioned as unique among minerals in the harm that they cause. The discursive process of creating the conflict minerals narrative tied the bad parts of extraction - child labour, funding war, and environmental damage - to these mines in the DRC rather than to extraction more broadly. The many thousands of other extractive sites and the materials that come from them remain dis-origined and supposedly conflict-free.

This discourse also shows up in science in the treatment of materials as always representing their universal selves. In a paper detailing various social identities of gold, Oakley (2015) identifies this as the 'elemental' mode of considering a material. In this mode, materials like gold are considered identical to their atomic identity, describable only through properties which are (or could be) written on the periodic table. This is technically almost never accurateeven high-purity samples used in materials science labs, which may be $99.99999 \%$ or more made of the atom of interest, are not elementally pure. The impurities come from ores the metal was a part of and environmental interactions it may have had on its way from the mine site through the smelter. Might these impurities and their geological origins ever have an effect on experiments? It is unlikely ${ }^{2}$ but not impossible. Could there be scientifically relevant conclusions missed because the origin of materials is considered irrelevant?

As a final example, consider reporting on the environmental impact of technologies from computers to cars. The focus is on the carbon created by operating these technologies (e.g. Stoll et al. 2019; Manne 2020). Bitcoin mining, or crypto-mining more generally, uses enormous amounts of electricity for operating computers. More carbon is emitted annually in the mining of bitcoin specifically than from the entire country of Jordan (Stoll et al. 2019). But, even though the specialized computer rigs are mentioned in reporting on this, the carbon emissions or habitat destruction it took to produce them and the metals that make them up are often not included (Manne 2020; Aratani 2021). Electric cars, too, are made up of materials that come from the ground. Notably, an enormous amount of lithium and cobalt make up their batteries - so much that demand for these metals is predicted to far exceed their available reserves on earth (Marx 2019). Regardless of how much there is, the socio-ecological harm with extracting these and the dozens of other metals in electric cars is enormous and is so much more than carbon emissions produced through the production of electricity for their operation (Center for Interdisciplinary Environmental Justice et al. 2019).

\subsection{Structural erasure of information}

The second interwoven part of dis-origining is the lack of information. Not only is there this major discourse where origins do not exist, but if one wants to find the origins of some material, it is incredibly difficult. Information is discarded, intentionally and unintentionally, from both the data available about materials and the physical instantiation of the material.

In terms of the data or stories available about a particular bit of material, many mechanisms

\footnotetext{
${ }^{2} \mathrm{As}$ in the case of a largely dismissed claim that the radioactive decay of certain isotopes depended on our position in our orbit around the sun (Schrader 2016) - the discussion of which nonetheless would not have been possible without scientists recording the date of their measurements.
} 
function together to discard information. Companies refuse to publicly disclose suppliers because that information is relevant to their market value. Materials may pass through a dozen or more companies, including shippers, to arrive at a public retailer (Rauer and Kaufmann 2015). Often materials travel thousands of kilometres. Resource geographers have done a lot of work to try to keep track of things as they pass through different supply chains, attending to social and economic processes along the way (e.g. Forman and Balayannis 2020; Cook and et al. 2004). Some of this work has shown that neo-colonial structures of outsourcing and just-intime production makes tracking materials difficult (Hulme 2017). Geographies of dissociation attend to companies intentionally obscuring their relationships with various suppliers or consequences of their work, which can include socio-ecological damage from extraction (Ibert et al. 2019). Companies also intentionally manufacture ignorance or alternative narratives about the way that their operations affect people and planet (Oreskes and Conway 2010). Usually, the stripping in these cases is intentional, whether it is a system designed to focus on capitalist value to the exclusion of origin or an executive board who intentionally obfuscates emplaced violence.

The other part of this informational stripping is the parts that are unavoidable with extraction. Even if stories about the mines materials came from were readily told, there is other information that is necessarily lost in extraction. This is a physical sort of loss; in going from part of a mountain to classified ore to hewn rock to milled concentrate to smelted pure metal and beyond, physical details are lost. What kind of ore was a piece of $99.999 \%$ pure nickel a part of? Nobody can tell just by analysing the metal. Physically removing signifiers of place is an unavoidable part of extraction.

\subsection{Compartmentalized reasoning}

The final element of dis-origining is compartmentalized reasoning about materials. Even when people are quite aware of and opposed to socio-ecological harm in the production of something, few are likely to change their behaviours because of it. Methods of coping with this cognitive dissonance include having different 'moral circles' in which to reason about moral obligation to actors (Te Velde et al. 2002). A classic example of this is people who care deeply for the welfare of pets but who also eat slaughterhouse-killed animals (Kunst and Hohle 2016). This is a roadblock that resource geographers mentioned above have run into with the diminishing effectiveness of showcasing where commodities come from (Duncombe 2012). From the perspective of dis-origining, these dissonances highlight how emplaced socio-ecologies of origin are not seen as part of things, even when there is awareness of socio-ecological violence at the place of origin.

\section{Contrasting dis-origining with existing theoretical concepts}

The three elements of dis-origining describe something that I saw in studying physics labs, and eventually in most places I looked. I saw these disconnects between people and where things came from, but I could not find adequate existing language to describe what I saw. So, it seemed useful to coin a new term. Dis-origining has overlap with several existing terms, though. In this section, I elaborate on the differences and similarities with each extant concept in turn. The goal here is to both deepen the theorization of this new term and to argue that it is more useful for describing how stuff seems to come from nowhere than any of the already 
existing language.

The main difference running through all comparisons is that dis-origining takes origin as central. Materials are from somewhere. In that place they already have relationships. Taking them out of that place injures or destroys those relationships. Places and their constitutive relationships are incredibly important, as rich socio-ecologies are generative of life.

More specifically, Haraway's (1988) god-trick is about knowledge from nowhere-but disorigining is about stuff from nowhere. Environmental alienation describes a separation between humans and nature in Marxist language. But this requires a definition of nature - something that is rather notoriously difficult to come by (e.g. Latour 2012). The commodity fetish, another Marxist concept, locates the problem in essentializing all of our exchanges of stuff into monetary exchanges, which obfuscates the social relations that made that stuff. This describes the root of many of the problems of capitalism, which is very helpful, but does not quite get at the problems of taking rock out of the ground to make stuff. Finally, geographers Ibert et al. (2019) have recently coined the term dissociation to describe how brands intentionally obfuscate connections across geographies, but this again elides extraction.

I start below with Haraway's god-trick and move through environmental alienation, the commodity fetish, and finally geographies of dissociation, arguing along the way for the utility of this new word.

\subsection{Stuff from nowhere and the view from nowhere}

Haraway's (1988) famous god-trick is a description of a widespread epistemological problem where it is assumed that one can know something disconnected from one's own context. Classic notions of objectivity make it seem as though the knower is a god, who can look upon things from nowhere, and thus see things untainted by social context. Though the discursive parts of the view from nowhere and dis-origining are similar, I prefer this new term in order to turn the focus more explicitly towards materials, extraction, and ecology/place.

Dis-origining is similar to the god-trick. It is certainly a trick. Knowledges are always situated, and stuff is always from somewhere. If we consider knowledge as a material, these two tricks are nearly the same. There is, however, a distinction I would like to make, centering around the part of dis-origining I identified above as inherent to extraction. The production of knowledge is not an inherently extractive process. Identifying and working with its situatedness adds to knowledge. It becomes not just a thing, but a thing-in-context, with its specific knowers and actors and history. Harding would say it has strong objectivity (Harding 1992). Relationships can be attended to by including this context. Pretending to a view from nowhere is epistemic violence (e.g. Namaste 2009), and it can mask other violences, but this violence can be largely addressed through attending to situation.

A dis-origined material has been extracted. Maintaining knowledge of its physical path through the world and the hands which shaped it (and have been shaped by it) could certainly help people attend to some of the relationships involved. But adding more knowledge does not fix dis-origining. There are parts of dis-origining unavoidable in extraction. We cannot situate the details of a mountain ecosystem back into the silicon in our electronic devices (Scott 2021). Some knowledge is lost. In other words, the political impetus readily associated with the godtrick is to document and retain knowledge about where knowledge comes from. The political impetus of dis-origining certainly lends itself to retaining knowledge about where things come 
from, but it goes further. The goal is to retain more of the relationships that materials have in their origins - to reduce socio-ecological violence of extraction.

\subsection{Environmental alienation}

Dis-origining also has overlap with the eco-marxist concept of environmental alienation. In eco-socialist theorist Peter Dickens' account, discussed by James Ormrod (2016), this type of alienation is at the core of our current economic and social woes. Dickens' defines environmental alienation through its two main aspects. First, humans do not understand 'nature.' Dickens asserts that the cause of this broad sense of alienation is division of labour-separating each job into something distinct especially through dividing tasks and knowledge, generally in the name of efficiency and expertise. Second, and to be defined in more detail below, capitalist operations create metabolic rifts.

\section{Lacking an understanding of nature}

The first part of environmental alienation - that humans lack an understanding of naturerequires a definition of 'nature'. This word is notoriously slippery, and indeed using it at all is criticized as being essentializing. This critique has been made of environmental alienation many times (Soper 2016). It has also been appreciated for retaining some aspect of nature which is 'real' i.e. is separate from social control (Soper 2016). While I align myself with discourses that do not often use the term 'nature' and attempt to not essentialize it, I sense there is more overlap in this piece than language may indicate. In dis-origining, there is an absence of knowledge of socio-ecological relationships, with an emphasis on stable though dynamic systems of such relationships. This is not a category with as much stability as 'nature', but the spirit of the ideas are quite similar.

A main difference is dis-origining's focus on materials versus alienation's focus on human experience. Humans are alienated; things are dis-origined. Another is the theoretical core. Alienation comes from understanding the world through labour; dis-origining comes from placeand socio-ecology-focused thinking.

\section{The metabolic rift}

There is more overlap in spirit with the second part of environmental alienation, the metabolic rift. Bellamy-Foster and Clark (2004) define the metabolic rift as when capitalist modes of production make gaps in the processes of ecosystems. Dis-origining is part of what happens when a metabolic rift is created and part of what makes it possible. To know the emplaced ecosystem that a material comes from and to still take from it would be to knowingly do violence.

But Dickens sees the metabolic rift and the lack of human understanding of nature as not necessarily linked; rather, understanding nature is important for "produc[ing] the things we need, and hence reaffirming our genuinely creative human powers (see Dickens 1997, p. 83)" (Ormrod 2016, p. 58). In contrast, talking about dis-origining as a part of the problem of extractivism asserts a likely irreducible link between extractivist understandings of the world and the catastrophic socio-ecological consequences of extractivism.

Finally, the literature surrounding environmental alienation is massive, dense, and, at times, 
convoluted. Some critics of Marx maintain that he saw nature as something to be conquered (see discussion in Foster and Clark 2016, p. 111). Eco-socialists, in contrast, hold that he saw nature as the source of all wealth ${ }^{3}$ and the eco-social metabolism as something which must be respected and worked within. This debate is not one I intend to wade into, though I appreciate its importance.

In covering all of these sometimes ambiguous ways that humans are separated from socioecology, environmental alienation is theoretically muddy. It would be clearer and thus more helpful for political motivation to speak of the specific ways that human activities are socioecologically harmful without essentializing nature. The metabolic rift does speak to this quite well. Dis-origining is another term which is more specific and useful than environmental alienation. It describes a particular set of ways that knowledge of socio-ecologies is discarded. It also focuses on place and relationships in ways that are less central to most Marxist perspectives.

\subsection{Commodity fetishism}

The commodity fetish is a central element of Marxist theory. Marx's originally defined the concept in the following (somewhat simplified) way. Capitalist markets allow people to exchange items that serve very different purposes (Marx 1976). His original example was a coat for linen (Marx 1976, p. 132). Coats have a different use (or use-value) than linen, but assigning a monetary exchange-value to each of them allows for trade. Capitalist economies have a hyper-focus on exchange-value. In other words, objects are fetishized into commodities. According to Marx, this focus means that people think about exchange as relationships between things instead of relationships between people (Marx 1976, p. 166). In other words, capitalism focuses our attention on stuff and thus obfuscates how that stuff was made and who made it.

The main overlap of dis-origining and the commodity fetish is in the obfuscation of the conditions of production. By centralizing the commodity in our lives, capitalism produces a world where things come from the store and you acquire them by paying money. Everything that it took to make whatever is being purchased is invisibilized. The only thing that is relevant to whether you can acquire an item is whether you can pay the price - the exchange-value.

But the commodity fetish does not capture the whole picture, and may point in directions for action which are not the most helpful. First, the commodity fetish is central to capitalism. Opposing it requires opposing capitalism, and vice versa. That is definitely necessary. But capitalism is not the entire problem. Certainly, the way that we extract today is capitalist, but that is a contingent position. We could address the particular construction of exchange-value in a capitalist market and still be extractivist. This is particularly likely if we remain shortsightedly anthropocentric in considering the use-value of things. What is the use for humans of pulling metals out of the ground to make physics experiments happen? What about for an entire socio-ecology?

Second, the commodity fetish does not recognize place or extraction from it. In contrast, disorigining highlights the removal and purification of materials from origin. Third, and related, the commodity fetish focuses quite exclusively on the conditions of production rather than the conditions of extraction. It is not as if there is a binary of production/extraction KilloranMcKibbin and Zalik (2016). But much of the language of the commodity fetish is about production without talking about extraction - for instance, referring to "environmental inputs"

\footnotetext{
${ }^{3}$ where wealth is use-value, distinguished from exchange-value which is made through capitalist processes.
} 
to "the production of commodities" (Castree 2001, p. 1522). This hyper-focus on production does not adequately point towards problems inherent in extractive production, even if they are operated in socialist ways. dis-origining, in contrast, emphasizes the extractive nature of production.

In addition to these distinctions, the commodity fetish is the subject of a lot of debate. There are disputes over what fetish exactly is the problem. Some hold it is only the capitalist market-produced price (Cook and Woodyer 2012; Stallybrass 1998), while others suggest it is meaning-making in general (Latour 1999; Ermann 2011). dis-origining (hopefully) avoids these and other debates.

Finally, and related to this last point, the commodity fetish is a difficult concept to work with. It is not clearly related to place, socio-ecology, or extraction upon first (or second) glance. I had a difficult time going through the literature to get a reasonable understanding of contemporary usage of the term. I am not opposed to theory which requires explanation (as evidenced by this paper) but I believe dis-origining gets more quickly at the core of the particular issue of structural ignorance about the placed socio-ecologies that materials are extracted from.

\subsection{Geographies of dissociation}

Geographers Ibert et al. (2019) have analysed dissociations that corporations enact between themselves and parts of their operations which could negatively impact the capitalist market value of their brand. This is clearly a crucial element of dis-origining. Corporate decisions to not acknowledge their sources or to even willfully create ignorance of them informatically disorigins materials. Ibert et al. (2019) also include consumer agency in dissociation, as discussed in compartmentalization. The first major distinction between dissociation and dis-origining is that dis-origining is inherent in extraction while dissociation is not.

The second major distinction is again about focus on capitalism. Dissociation usefully describes the actions that corporations take to create positive value or protect against negative value in capitalism markets. Value is also not the only thing we need to pay attention to. What is there to focus on beyond capital? Beyond extraction? What would an origined world look like? The theory here does not aim to prescribe this. It just points towards maintaining relationships of socio-ecology rather than only against capitalist value relations.

\section{Responsibility and re-origining}

Having just elaborated on what dis-origining is, I now turn to what dis-origining prevents us from doing and how we might overcome that. I start with discussing responsibility in relationships that dis-origining (among other things) limits us from acting on, then turn to one possible method to move towards responsibility: re-origining.

Origins are emplaced, historied relationships among more-than-human beings and bodies often considered abiotic, including rocks. Extraction violently breaks many of these relationships. Dis-origining obfuscates the breaking, the history of relationships, and the very real relationship of that origin to the smelted, processed, dis-origined material. Between metal in the lab and a mine is an unbreakable relationship of causation: the metal came from the mine. In that provision, people and institutions who use metals enter into a relationship with the place of the mine. 
We could consider responsibility to be about acts of care within relationships. We could also consider it to be about addressing and preventing violence as much as possible, especially in situations where we are affected by or gain something from that violence. Settler colonialism is a good example: settlers in genocidal states like Canada have a responsibility to address the ongoing violence of the state, because they are a part of the colonial relationship, even if they did not actively decide to be. People who use violently extracted materials have a responsibility to those materials and origins, even if they did not actively choose to pull them out of the ground. They are in relationship.

What would responsibility look like in a lab where all of the materials came violently from the ground? In studying those labs? Likely, it would mean at least that we would consider the problems of extraction as intimately tied up in all the problems of technoscience. We would focus on the fact that a huge amount of the material technoscience that we have and do only exists because extraction does. We would probably need to do a lot more than that to really be responsible - just like the responsible thing to do as a settler is to participate in decolonization, not just talking about how bad things are. But the focus on extraction is certainly a necessary step. This focus is, however, obscured by dis-origining.

One course of action to get past this obfuscation is suggested fairly clearly by even the word 'dis-origin'. This is to tell stories about origins, a sort of re-origining. This practice has been enacted before in great detail by resource geographers, who call it "following the thing" (Cook and et al. 2004). A clear thread in much of this research is to 'get behind the veil' of the commodity fetish and alert people to the 'reality' of the stuff they buy (Harvey 1990). But even being able to produce such stories has become harder in recent years. Just-in-time logistics, cargo falling off of ships, and complex outsourcing sometimes make it impossible even for professional geographers to follow things (Hulme 2017). One strong criticism of this tactic is that it is only so motivating. Nearly everything in this extractivist hell comes from some violent origins, and most people know this on some level, even if they are compartmentalizing it away. Reading another investigative piece about it has become less and less likely to be effective (Duncombe 2012).

STSers, however, are not typically in the business of shocking consumers into changing their habits. If an STSer is interested in attending to relationships that produce technology, extraction of the materials it is made out of and the harm that does to existing socio-ecological relationships is very relevant. Though following the thing or studying the origin of something is not sufficient as a tactic, it seems necessary.

Scientists and tech workers are, additionally, not well described by the term 'consumer'. They purchase items within the constraints of a capitalist economy and the constraints of being compelled to produce research of a certain kind to be employed and respected in their fields. They produce research and things which are sometimes commodified or mass produced. They have relationships which they have a very active role in creating, in some contrast to a consumer at a grocery store. Perhaps there is a power there. As a part of production of tech, what might happen if scientists refused to produce? How might attending to the unavoidability of extraction in technoscience encourage scientists to refuse unnecessary production?

\section{Conclusions}

In new materialist traditions of STS, things are incredibly important, as are locations and 
contexts. In this paper, I have argued that the context of origin is also important, especially the socio-ecological relationships that were harmed or brutally broken in the process of extraction.

I have contributed the theoretical concept of dis-origining. This word describes the ways that information about and consideration of origin and extraction is invisibilized in materials and the technologies that they make up. I have argued that it is more useful than Marxist terms like the commodity fetish and environmental alienation to describe this specific invisibilization.

I have couched this contribution in a broader argument: extraction inheres in contemporary material technoscience. Tech is made of stuff, and that stuff is from the ground. Lab workers and STSers alike work with the material fruits of colonial extraction, whether in lab equipment or computers. They also work within the epistemic frame of dis-origining, which acts as a crafted barrier in the landscape of science, encouraging workers down the normative extractive path, even if they are physically removed from mine sites. Tearing that barrier down, bit by bit, is part of what must happen to make scientific practice non-extractive and non-colonial.

But knowing where things come from is hardly the only thing that has to happen for material responsibility. The harm of extraction has to be addressed and reduced. Extraction itself, in all the deep ways it is enmeshed within technoscience, has to be refused. What would technoscience look like then?

\section{Acknowledgements}

Thanks to Elizabeth Patitsas for extensive comments and suggesting that compartmentalization was a part of dis-origining. Thanks to Allison Gonsalves and Dawn Wiseman for very helpful feedback. I wrote this paper on a desktop computer with a massive screen, resting on a desk made of pine, in a house made of brick and steel, on a street made of asphalt, on colonially occupied land. I do not know where these materials come from. I do not know how to acknowledge them. But this paper has its origins in them too.

\section{References}

Anusas, M. and Ingold, T. (2013). Designing environmental relations: From opacity to textility. Design Issues, 29(4):58-69.

Aratani, L. (2021). Electricity needed to mine bitcoin is more than used by 'entire countries'. The Guardian.

Arboleda, M. (2020). Planetary Mine. Verso Books.

Azadi, M., Northey, S. A., Ali, S. H., and Edraki, M. (2020). Transparency on greenhouse gas emissions from mining to enable climate change mitigation. Nature Geoscience, 13:100-104.

Barad, K. (2007). Meeting the Universe Halfway. Combined Academic Publ.

Bellamy-Foster, J. and Clark, B. (2004). Ecological imperialism: The curse of capitalism. Socialist Register, 40(1):186-201.

Bernauer, W. (2019). The limits to extraction: mining and colonialism in nunavut. Canadian Journal of Development Studies / Revue canadienne détudes du développement, 40(3):404-422.

Camastro, S. (2019). Building an ethic of responsibility in indigenous solidarity. In Showing Up for Racial Justice - Toronto's Intro to Anti-racism Mini-series. SURJ. 
Cameron, E. and Levitan, T. (2014). Impact and benefit agreements and the neoliberalization of resource governance and indigenous-state relations in northern canada. Studies in Political Economy, 93(1):25-52.

Carpenter, R. P. (2012). The bottom of the smart weapon production chain: Securing the supply of rare earth elements for the u.s. military. Public Contract Law Journal, 41(2):411-433.

Castree, N. (2001). Commodity fetishism, geographical imaginations and imaginative geographies. Environment and Planning A, 33:1519-1525.

Center for Interdisciplinary Environmental Justice, Brito-Millán, M., Cheng, A., Harrison, E., Mendoza Martinez, M., Sugla, R., Belmone, M., Salomón, A., Quintanilla, L., Guzman-Morales, J., and Martinez, A. (2019). No comemos baterías: Solidarity science against false climate change solutions. Science for the People, 22(1).

Cervantes, A. H. and Zalik, A. (2018). Canadian capital and the denationalization of the mexican energy sector: A geojuridical approach. Journal of Latin American Geography, 17(3):42-72.

Cook, I. and et al. (2004). Follow the thing: Papaya. Antipode, 36(4):642-664.

Cook, I. and Woodyer, T. (2012). The Wiley-Blackwell Companion to Economic Geography, chapter Lives of Things, pages 226-241. Blackwell Publishing, first edition.

Coulthard, G. (2014). Red Skin, White Masks: Rejecting the colonial politics of recognition. U of Minnesota Press.

Denzin, N., Lincoln, Y. S., and Smith, L. T., editors (2008). Handbook of critical and Indigenous methodologies. Sage, Los Angeles.

Duncombe, S. (2012). It stands on its head: Commodity fetishism, consumer activism, and the strategic use of fantasy. Culture and Organization, 18(5):359-375.

Eglash, R., Drazan, A. B. J., Lachney, M., and Babbitt, W. (2017). A mathematical tool kit for generative justice. ETD-Educaçāo Temática Digital, 19(3).

Ermann, U. (2011). Brands and Branding Geographies, chapter Consumer capitalism and brand fetishism: The case of fashion brands in Bulgaria, pages 107-124. Edward Elgar Publishing.

European Commission (2020). Conflict minerals: The regulation explained. Technical report, European Commission.

Forman, P. and Balayannis, A. (2020). Call for proposals: On methods of thing-following. RGS-IBG Annual International Conference.

Foster, J. B. and Clark, B. (2016). Changing Our Environment, Changing Ourselves: Nature, Labour, Knowledge and Alienation, chapter Marx's universal metabolism of nature and the Frankfurt School: Dialectical contradictions and critical syntheses, pages 101-136. Palgrave Macmillan.

Fox, N., Graham, L. J., Eigenbrod, F., Bullock, J. M., and Parks, K. E. (2020). Incorporating geodiversity in ecosystem service decisions. Ecosystems and People, 16(1):151-159.

Fritz, M., McQuilken, J., Collins, N., and Weldegiorgis, F. (2018). Global trends in artisanal and small-scale mining (asm): A review of key numbers and issues. Technical report, International Institute for Sustainable Development.

Girvan, N. (1976). Conflict Imperialism: Conflict and Expropriation, chapter 5: Towards a Minerals Policy for the Third World, pages 188-199. M. E. Sharpes.

Global Witness (2020). Defending Tomorrow: The climate crisis and threats against land and environmental defenders. Technical report, Global Witness. 
Gordon, T. and Webber, J. R. (2018). Canadian capital and secondary imperialism in latin america. Canadian Foreign Policy Journal, 25(1):72-89.

Gruenewald, D. A. (2003). The best of both worlds: A critical pedagogy of place. Educational Researcher, $32(4): 3-12$.

Gudynas, E. (2013). Beyond Development: Alterative Visions from Latin America, chapter Transitions to post-extractivism: directions, options, areas of action, pages 165-188. Fundación Rosa Luxemburg.

Haraway, D. (1988). Situated knowledges: the science question in feminism and the privilege of partial perspective. Feminist Studies, 14(3):575-599.

Haraway, D. (2016). Staying with the Trouble: Making Kin in the Cthulucene. Duke University Press.

Harding, S. (1992). Rethinking standpoint epistemology: What is "strong objectivity?". The Centennial Review, $36(3): 437-470$.

Harvey, D. (1990). Between space and time: Reflections on the geographical imagination. Annals, Association of American Geographers, 80(3):418-434.

Hill, S. (2017). The clay we are made of : Haudenosaunee land tenure on the Grand River. University of Manitoba Press, Winnipeg, Manitoba, Canada.

Hosgood, A. F. (2020). Security camera captures heavily armed rcmp at wet'suwet'en cultural site. The Tyee.

Hulme, A. (2017). Following the (unfollowable) thing: methodological considerations in the era of high globalisation. cultural geographies, 24(1):157-160.

Ibert, O., Hess, M., Kleibert, J., Müller, F., and Power, D. (2019). Geographis of dissociation: Value creation, 'dark' places, and 'missing' links. Dialogues in Human Geography, 9(1):43-63.

INET (2017). Standing rock of the north: the kinder morgan trans mountain pipeline expansion secwepemc assessment. Technical report, Indigenous Network on Economies and Trade.

Ingersoll, K. (2016). Waves of knowing : a seascape epistemology. Duke University Press, Durham.

Killoran-McKibbin, S. and Zalik, A. (2016). Rethinking the extractive/productive binary under neoliberalism. Routledge.

Kunst, J. R. and Hohle, S. M. (2016). Meat eaters by dissociation: How we present, prepare and talk about meat increases willingness to eat meat by reducing empathy and disgust. Appetite, 105(1):758-774.

Kuokkanen, R. (2000). Towards an "Indigenous paradigm" from a Sami perspective. The Canadian Journal of Native Studies, XX(2):411-436.

Kuyek, J. (2019). Unearthing justice : how to protect your community from the mining industry. Between the Lines, Toronto.

Latour, B. (1999). Pandora's Hope: Essays on the Reality of Science Studies. Harvard University Press.

Latour, B. (2012). We Have Never Been Modern. Harvard University Press.

Manne, S. (2020). Examining the carbon footprint of devices. Sustainable Software: Microsoft DevBlog.

Marx, K. (1976). Capital: Volume I, chapter Chapter 1: Commodities, pages 125-175. Penguin Books.

Marx, P. (2019). The electric vehicle revolution will be dirty and unequal. Radical Urbanist.

Meshake, R. (2016). Oral storytelling. In Integrating Knowledges Summit: A Truth and Reconciliation Response Project Decolonizing Education.

MiningWatch Canada (2020). Mine Waste in Canada: A Growing Liability. MiningWatch Canada Blog. 
Mitchell, T. (2009). Carbon democracy. Economy and Society, 38(3):399-432.

Moore, J. and Perez-Rocha, M. (2019). Extraction casino: mining companies gambling with latin american lives and sovereignty through supranational arbitration. Technical report, MiningWatch Canada, Institute for Policy Studies, Center for International Environmental Law.

Namaste, V. (2009). Undoing theory: The "transgender question" and the epistemic violence of Anglo-American feminist theory. Hypatia, 24(3):11-32.

Nolan, T. (2020). How militarizing police sets up protesters as 'the enemy'. The Tyee.

Oakley, P. (2015). The Social Life of Materials: Studies in Material and Society, chapter Introducing Fairtrade and Fairmined gold: An attempt to reconfigure the social identity of a substance, pages 155-174. Bloomsbury.

Oberle, B., Bringezu, S., Hatfield-Dodds, S., Hellweg, S., Schandl, H., and Clement, J. (2019). Global resources outlook 2019: Natural resources for the future we want. Technical report, United Nations Environment Program.

Oreskes, N. and Conway, E. M. (2010). Merchants of Doubt. Bloomsbury.

Ormrod, J. (2016). Changing Our Environment, Changing Ourselves: Nature, Labour, Knowledge and Alienation, chapter Fragmenting nature: Themes in Peter Dickens's work, pages 37-78. Palgrave MacMillan.

Paperson, L. (2014). A ghetto land pedagogy: An antidote for settler environmentalism. Environmental Education Research, 20(1):115-130.

Radley, B. and Vogel, C. (2015). Fighting windmills in eastern congo? the ambiguous impact of the 'conflict minerals' movement. The Extractive Industries and Society, 2(3):406-410.

Rauer, J. and Kaufmann, L. (2015). Mitigating external barriers to implementing green supply chain management: A grounded theory investigation of green-tech companies' rare earth metal supply chains. Journal of Supply Chain Management, 51(2):65-88.

Schrader, H. (2016). Seasonal variations of decay rate measurement data and their interpretation. Applied Radiation and Isotopes, 114:202-213.

Scott, D. T. (2021). 'we don't even know who owns it': the infrastructural imaginary of spruce pine, NC. Cultural Studies, pages 1-20.

Seawright, G. (2014). Settler traditions of place: Making explicit the epistemological legacy of white supremacy and settler colonialism for place-based education. Educational Studies, 50(6):554-572.

Simpson, L. B. (2008). Looking after gdoo-naaganinaa: Precolonial nishnaabeg diplomatic and treaty relationship. Wicazo Sa Review, 23(2):29-42.

Simpson, L. B. (2011). Dancing on Our Turtle's Back: Stories of Nishnaabeg Re-Creation and a New Emergence. Arbiter Ring Pub.

Slowinski, G., Latimer, D., and Mehlman, S. (2013). Dealing with shortages of critical minerals. ResearchTechnology Management, pages 18-24.

Soper, K. (2016). Environmental alienation.

Stallybrass, P. (1998). Border Fetishisms, chapter Marx's coat, pages 183-207. Routledge.

Stoll, C., Klaaßen, L., and Gallersdörfer, U. (2019). The carbon footprint of bitcoin. Joule, 3(7):1647-1661.

Te Velde, H., Aarts, N., and Van Woerkum, C. (2002). Dealing with ambivalence: Farmers' and consumers' perceptions of animal welfare in livestock breeding. Journal of Agricultural and Environmental Ethics, 15(2):203219. 
Watts, V. (2013). Indigenous place-thought \& agency amongst humans and non-humans (first woman and sky woman go on a european world tour!). Decolonization: Indigineity, Education, 8 Society.

\section{Affiliation:}

Emma McKay

Social Studies of Computing Lab

McGill University

Montréal, Canada

E-mail: emma.m.mckay@mail.mcgill.ca 